\title{
Logistics Coordination Management Mechanisms
}

\author{
Yan-Ling Wang ${ }^{1,2}$ \\ ${ }^{1}$ Zhejiang Wanli University, 315100 Ningbo, Zhejiang, P. R. China \\ ${ }^{2}$ Dalian Maritime University, 116026 Dalian, Liaoning, P. R. China \\ E-mail: yanling_wang1@yahoo.com.cn
}

Keywords: Logistics supply chain; multi-agent, flexibility, responsibility, coordination.

\begin{abstract}
Order to improve competitiveness in the logistics supply chain management of fisheries has become an increasingly important fishery enterprise, especially fisheries major retail enterprises. Logistics supply chain management has become part of the agenda of senior management in fisheries production and the retail industry to improve organizational efficiency and improve customer value, better use of resources and improve profitability and achieve organizational goals. In this article, the fisheries supply chain coordination problems. Multi-agent system, it can effectively deal with the distributed large-scale data, the coordination of fisheries development of retail logistics supply chain, warehouse and cross-pier is open, in this paper operation. To meet the individual needs of different participants in the proposed multi-agent system architecture for an efficient, responsive logistics supply chain coordination methods. The proposed multi-agent system can adaptively change over time, when the new organization is involved and the other disappeared. Proposed multi-agent systems, improve the level of the fisheries supply chain flexibility, the more sensitive members of the fisheries supply chain.
\end{abstract}

\section{Introduction}

Logistics supply chain management has become an increasingly important fishing enterprises, especially in the fisheries of the major retail enterprises in the fisheries industry, the logistics supply chain management has become part of the agenda in the senior management of the fishery production and the retail industry. In the real world, the fisheries production and competition for customers is not simple, as long as the central place theory proposed by Losch [1]. In the central place theory, the flow of goods between the central and local, can be described as input-output matrix. However, the emergence of the global economy and increased competition, leading to its fisheries rapid product introduction and innovation, in the fishing industry, many companies recognize the importance of supply chain management to the market. In order to improve their competitiveness, many companies in the fisheries industry has accepted the fisheries supply chain management to improve organizational effectiveness and achievement of organizational objectives, increase customer value, better use of resources, and improve profitability. In addition, the availability of certain goods in a central place depends on the production, transportation and supply chain. The various methods described for a set of resources into another set of resources, production, inventory, transportation and consumption, can be found in the literature. Consider to adhere to the enterprise operational efficiency to improve collaboration between business partners and clients respond to modern management advocates, and an additional thrust towards a successful competitive strategy. Consider adhere to enterprise operational efficiency to improve collaboration and client response in the modern fisheries management advocated by business partners, an additional thrust towards a successful competitive strategy. Therefore, supply chain management in the fisheries industry has become part of the agenda of the senior management of the fishery production and the retail industry. Fisheries production and retail counterparts in the fisheries industry executives all know that successful coordination, integration and management of critical business processes, the entire members of the fisheries supply chain will ultimately determine the success of their competition. In the modern retail environment, fisheries, fisheries, retailers have to deal with domestic and global competition by traditional and 
non-traditional channels. In addition, managers are increasingly aware that they no longer compete fully self-governing entity in the fisheries industry. On the contrary, the competition between the fisheries supply chain. In addition, managers are increasingly aware that they no longer compete fully autonomous entity. On the contrary, the competition between the fisheries supply chain. The National Fisheries retail chains and networks play an important role in developing countries, as well as local, regional and export markets, provide market access for producers. National Fisheries retail competitiveness of industrial enterprises, small and large there will be innovation and reduce costs, and more responsive to consumer demand, the retail system in the national fisheries. This can help fisheries supply chain management in national Fisheries retail system. Simply ignored the National Fisheries retail supply chain to increase future losses or business interruption potential and possibilities. In recent years have seen the increasing globalization of markets and their core competitiveness of enterprises are concentrated. Individual companies are no longer as an independent entity with a unique brand competition, but as an integral part of the logistics supply chain. More and more companies have begun to realize the importance of strategic planning, control and design of the logistics supply chain as a whole. Therefore, the ultimate success of an enterprise depends on its management capacity, the complex network of business relationships between the integration and coordination of the logistics supply chain members, legally and economically independent companies are increasingly involved in the increase in the value of part of the process of the entire logistics supply chain. Coordination and cooperation between the need to increase the company, as well as logistical decision-making in the interest of the fisheries supply chain management field is the growth of recent scholars and practitioners. Fisheries logistics supply chain is a distributed system, distributed large-scale data should be correct, in the fisheries supply chain coordination and risk control. Therefore, effective, should be appropriate fisheries logistics supply chain coordination and risk control solutions [2]. Multi-agent system [3] - [5], it can effectively deal with large-scale data distribution, coordination Fisheries logistics supply chain, in order to control risk in this article. In the following, we will consider the fisheries logistics supply chain coordination and risk management mechanisms, based on multi-agent system. Multi-agent system development and coordination of fisheries supply chain logistics to warehouse and cross-terminals of the Fisheries major retail companies, has opened in this article operate risk management and supply and demand uncertainty. To meet the individual needs of different participants in the proposed multi-agent system architecture design in order to establish an efficient response quickly fisheries logistics supply chain coordination and risk management methods. The proposed multi-agent systems adaptive change over time, become the new organization and the other disappeared. Proposed multi-agent systems, improve the level of the fisheries supply chain flexibility, the more sensitive members of the fisheries supply chain.

\section{Problem Representation}

Fisheries logistics supply chain is referred to as an integrated system, and fishery raw materials and components is synchronized to a series of interrelated business processes: (1), (2) the raw materials and components of these fisheries, fishery products into the finished product, (3) These value-added fishery products, (4) distribution, and promotion of these aquatic or fisheries retailers or customers, (5) the promotion of various business entities (such as fisheries suppliers, manufacturers, distributors, third party logistics exchange of suppliers and retailers). Its main purpose is to improve the status of operational efficiency, profitability and competitiveness of a company and its supply chain partners. Fisheries logistics supply chain entities are highly interdependent, and to improve supply chain performance goals, such as cost minimization, quality assurance, on time delivery. Therefore, the performance of any entity in the fisheries supply chain depends on the performance of others, within the range of their ability to coordinate the activities of the fisheries supply chain [2]. Unlike traditional logistics, fisheries logistics supply chain management involves the independent operating companies to seek their own profit-maximizing coordination. Effective fisheries logistics supply chain 
management needs of members of the various channels, including fisheries coordination between retailers, manufacturers and intermediaries. Fisheries logistics supply chain management is a major problem fisheries logistics supply chain is controlled by individual companies to achieve the overall minimum cost, the company has opened in the management and operation of the warehouse and cross-pier in order to effectively manage risk. In addition, the mechanism must ensure that the existing supply chain partnership, each company will achieve the same profit, at least in the previous application mechanism. Lagrangian relaxation, dynamic programming methods, soft computing method, or a combination of the above method can be promising as a logistics supply chain coordination and risk management to be promoted. This suggests that upstream entities, suppliers and downstream entities, and consumers. Fisheries supply chain is a distributed system. Appropriate fisheries logistics supply chain coordination and risk management, distributed problem should be effectively addressed. In the following, we propose a proxy way to solve the fisheries logistics supply chain coordination and risk management issues, fisheries management across the country issued several major retail company. Multi-agent systems, including intelligent agents in a suitable software platform, distributed paradigm to solve the problem of effective technology. Fishery products, the National Fisheries retail companies, logistics managers must decide what kind of quality objectives and control methods, will be around the product or whether the process of organizational resources. , The company has opened run the warehouse and cross-Pier, it has to deal with fisheries logistics supply chain coordination and risk management issues. In other industries, such behavior is usually referred to as a business decision, or operate the infrastructure. Objective function of the fisheries, logistics and supply chain coordination and risk management issues, including the families of the warehouse, shipping and fishery products in order to minimize transportation costs, total cost, transshipment cost of cross-dock warehouse boat series from fishery products, and distribution costs to cross-dock ship from the client area of the product line, control risk, which can be expressed as [2], [3]

$$
\min \left\{C_{\text {Operations total }}=C_{\text {transportation }}+C_{\text {transshipment }}+C_{\text {distribution }}\right\}
$$

subject to

$$
\begin{gathered}
C_{\text {transportation }}=\sum_{i=1}^{I} \sum_{p=1}^{P} c_{\text {transportation } i p} b_{\text {transportation } i p} \\
C_{\text {transshipment }}=\sum_{i=1}^{I} \sum_{j=1}^{J} \sum_{p=1}^{P} c_{\text {transshipment } i j p} q_{i j p} \\
C_{\text {distribution }}=\sum_{j=1}^{J} \sum_{l=1}^{L} \sum_{p=1}^{P} c_{\text {distribution } j l p} q_{j l p} \\
b_{\text {transportation }_{i p}}=\sum_{j} q_{i j p} \quad \forall i \text { and } p \\
\sum_{i} q_{i j p}=\sum_{j} q_{j l p} \quad \forall j \text { and } p \\
\sum_{j} q_{j l p}=g_{l p} \quad \forall l \text { and } p \\
b_{\text {transportation }_{i p}} \geq 0 \quad \forall i \text { and } p \\
q_{i j p} \geq 0 \quad \forall i, j \text { and } p \\
q_{j l p} \geq 0 \quad \forall j, l \text { and } p
\end{gathered}
$$

where $C_{\text {Operations total }}, c_{\text {transportation }_{i p}}, c_{\text {transshipment } i j p}, c_{\text {distribution } j l p}, b_{\text {transportation }_{i p}}, q_{i j p}, q_{j l p}$, respectively, denotes, the total cost to be minimized, the transportation cost to deliver one unit of the $p$ th fishery product to the $i$ th warehouse, the cost to supply one unit of the ${ }^{p \text { th }}$ fishery product from the ${ }^{j \text { th }}$ cross-dock which would be used by the $l_{\text {th }}$ customer zone, the cost to transport one unit of the ${ }^{p \text { th }}$ fishery product from the $i$ th warehouse $\mathrm{k}$ to the ${ }^{j \text { th }}$ cross-dock, the amount of the product shipped to the $i$ th 
warehouse, the amount of the ${ }^{p \text { th }}$ fishery product shipped from the $i$ th warehouse to the $j^{\text {th }}$ cross-dock, the amount of the ${ }^{p \text { th }}$ fishery product shipped from the ${ }^{j \text { th }}$ cross-dock to the $l$ th customer zone. Constraint set (5) ensures that the total amount of products shipped into warehouses from the central manufacturing plant site is the same as the total amount of products shipped from warehouses to cross-docks. Set of constraints (6) to ensure that the total amount of the total amount of products shipped from warehouses to cross-dock is equal to the cross-pier shipped to the client area. The set of constraints (7) is to meet the needs of the constraints to restrict the product from the cross Pier shipped to the client area, equal to the total needs of the client area. Set of constraints (8) - (10) to ensure that all decision variables are non-negative. When the new organization is involved and the other disappeared, and how to improve the fisheries supply chain flexibility and a member of the fisheries supply chain (such as lead-time, the level of the response of the human processing time, inventory levels and the number of out of stock) become more important. In the following sections, the development of multi-agent system-based approach to coordinate fisheries logistics supply chain, and thus the uncertainty of the risk management of the fisheries major retail companies and supply and demand, the warehouse and cross dock has opened and operated in order to reduce the total cost. From the above discussion, it can be seen that the fisheries supply chain coordination and risk management involve different participants, including the process of interaction between human beings, human and information systems. This is a very difficult treatment facilities, and to determine $\sim$ the solution to meet the needs of different customers. Appropriate fisheries logistics supply chain coordination and risk management, distributed problem should be to solve large-scale distributed data between the different partners. In addition, the fisheries supply chain coordination and risk management is to adapt and change over time, because the new organization, may become involved in and others may disappear. Architecture design must meet the individual needs of different participants in order to establish efficient and responsive fisheries logistics and supply chain coordination and risk management methods. In the following, based on the multi-agent technology to build such a structure. The proposed multi-agent architecture, including vertical and horizontal fisheries supply chain coordination and risk management. Vertical fishery logistics supply chain coordination and risk management, including aggregation and hierarchy. Vertical fishery logistics supply chain coordination and risk management all the agents have the same purpose, but operating at different levels in the hierarchy. Higher-level agents to determine the constraints for the low-level agents. Each supplier, manufacturers, distributors, third party logistics providers and retailers, said agent of the organization. A collection of functional agents can be regarded as the agent of the organization. Only the organizational agents communicate with each other, and the interface between the agents of the organization, the corresponding definition. The organization added to each company the freedom of each agent's behavior. Therefore, with the same name and interface, but belong to different companies the agent can have a completely different logic. There are four types of the Organization for the fisheries supply chain coordination and risk management. (1). The manufacturer agent's goal to optimize their fishery production planning and resource utilization. (2). Dealer agent target balance supply and demand of fishery, in consultation with the fisheries supply and demand agents, and to minimize inventory and shortage of logistics supply chain for the entire fishery. (3). Suppliers and retailers, agents targeted to minimize their number out of stock customer satisfaction. (4). Third-party logistics providers, agents, targeted to meet the agents of manufacturers, distributors, agents, suppliers, agents, retailers, agents requirements. Manufacturer's agents, suppliers and retailers, agents are selfish. However, the agent of the dealer as an intermediary or broker for their aggregate the needs of all participants to deal with demand and negotiation of both supply and demand, in order to minimize out of stock. Dealer agent to perform the following functions (1). Requirements gathering and processing. (2). Decomposition of the demand and orders. (3). Matching supply and demand. (4). Optimize the supply chain re-allocation of stock. (5). Inventory holding, processing, and volatility. There are different types of functions in the different levels of coordination and risk management of the logistics supply chain agents, such as (1). Forecast. Prediction agent under a month during the annual forecast. (2). Summarize the projections. Summarize the projections 
forecast the general agent and explain the prediction agent to provide. Forecast to take into account seasonal effects, the enema. (3). Long-term fisheries production planning. Long-term production planning agent to retain production capacity, and the constraints of the monthly production plan. This involves long-term fisheries planning, aimed at long-term retention of scarce resources identified on the basis of expected demand and fishery product prices. (4). Order. Arranged on behalf of the logistics planning agency ordered products. Logistics planning to modify or change the decisions made by these drugs may have a direct intervention. This agent to negotiate the right amount of product at the right time and order processing agent. (5). Order processing. Order processing agent to discuss the ordering agent, order allocation amount. Look at the actual inventory of these agents is expected to supplement priority booking agent and stock subscription agent changes. (6). Sports flow operating room. Physical flow of the daily day-to-day operations of the physical flow of control by the workers. Agent behavior can be seen from the above discussion, the use of multi-agent architecture can easily be changed, and use the vertical structure of the agent at different levels, can have varying degrees of automation, which can fully predict the level of human, ordering and monitoring level, you can perform the forecast level, which provides software agents operating within the limits of a gradual expansion of the automatic proxy settings. In addition, appropriate methods, such as Lagrangian relaxation, dynamic programming, soft computing method, or a combination of methods, can be effectively passed to solve large combinatorial problems of coordination and risk management, logistics supply chain for by each independent The company process control, in order to achieve the overall minimum cost, the company opened a major retail enterprises in the national distribution of each agent, the management of several product management of warehouse and cross-pier.

\section{Summary}

Multi-agent system coordination of fisheries development retail company's supply chain logistics, warehouse and cross-pier is open, operating in this article.

\section{Acknowledgments}

This work was supported in part by the National Soft Science Foundation of China (No. 2010GXS5D214), the Education of Ministry Humanities Social Sciences Research Project (No. 11YJA630135), the Science Foundation of Zhejiang Wanli University.

\section{References}

[1] A. Losch, The Economics of Location, New Haven, 1954.

[2] D. Simchi-Levi, P. Kaminsky and E. Simchi-Levi, Managing the Supply Chain - The Definitive Guide for the Business Professional, New York: McGraw-Hill, 2004.

[3] D. Simchi-Levi, P. Kaminski, Designing and managing the supply chain-concepts, strategies and case studies, New Jersey: McGraw-Hill, 2006.

[4] M. Wang, J. Liu, H. Wang, W. K. Cheung, X. Xie, "On-demand e-supply chain integration: A multi-agent constraint-based approach", Expert Systems with Applications, vol. 34, pp. 2683-2692, 2008.

[5] Q. Guo, M. Zhang, “A novel approach for multi-agent-based Intelligent Manufacturing System”, Information Sciences, Vol. 179, No. 18, pp. 3079-3090, 2009. 